\title{
Uma Ferramenta de Autoria para Criação de Websites por Crianças
}

\begin{abstract}
André Raabe*
Resumo: Este artigo apresenta o KidWeb - ferramenta para criação de websites por crianças. O KidWeb buscar auxiliar as atividades desenvolvidas com crianças da $3^{\mathrm{a}}$ e $4^{\mathrm{a}}$ séries do Ensino Fundamental baseadas na Pedagogia de Projetos. São abordados os estudos realizados sobre Pedagogia de Projetos, análise das interfaces de Editores HTML e ferramentas de autoria para crianças. A descrição do funcionamento do software e as perspectivas de utilização do mesmo no contexto escolar também são exploradas

\section{.Palavras-chave: Ferramentas de Autoria, Software Educacional, Pedagogia de Projetos}

Title: An Authoring Tool for the creation of websites by children

Abstract: This article presents KidWeb - a website construction tool for children, which is aimed at assisting activities carried out with children in the third and fourth grades of Elementary School, based on Education Through Projects. It addresses the studies already carried out in this area, analyses of the interfaces of HTML Editors and authoring tools for children. It also explores the way in which this software program operates and offers perspectives on its use in the school context.
\end{abstract}

Keywords: Authoring Tools, Educational Software, Teaching Through Projects

\section{Introdução}

Atualmente, o computador está inserido na realidade escolar servindo como uma ferramenta auxiliar que permite a criança envolver-se em experiências educativas, nas quais o processo de conhecimento contempla não só a teoria, mas também a prática.

Analisando as atividades desenvolvidas nas escolas do Ensino Fundamental que trabalham com a modalidade de Pedagogia de Projetos, percebeu-se que em grande parte das atividades desenvolvidas, as crianças são incentivadas a desenvolverem um produto final. Este geralmente é um documento, uma figura ou uma composição

* Doutorando em Informática na Educação - UFRGS; Coordenador do Grupo de Desenvolvimento de Software Educacional; Docente-Pesquisador do Curso de Ciência da Computação - CTTMar - Universidade do Vale do Itajaí - SC - Brasil; E-mail: araabe@cttmar.univali.br 
elaborada utilizando o computador. No entanto, grande parte das vezes, os softwares utilizados para suporte a estas atividades não são adequados à realidade e linguagem da criança.

Considerando esta realidade, decidiu-se desenvolver o KidWeb, uma ferramenta de autoria para auxiliar as crianças a elaborarem composições multimídia no formato de websites. Para isso, buscou-se desenvolver uma interface adequada a realidade da criança.

Este artigo está dividido da seguinte forma: a seção 2 apresenta os conceitos teóricos relacionados a Pedagogia de Projetos e Temas Geradores, e relata as visitas realizadas às escolas que trabalham com esta modalidade; a seção 3 apresenta a busca de indicadores para construção da interface do KidWeb; a seção 4 apresenta a descrição do KidWeb; a seção 5 elucida a relação do KidWeb com Pedagogia de Projetos; e a seção 6 apresenta as Considerações Finais.

\section{Pedagogia de Projetos}

Na Pedagogia de Projetos, os aspectos cognitivos, emocionais e sociais estão presentes na construção de conhecimentos, sendo colocados em prática por meio de atividades previamente elaboradas, nas quais aprender deixa de ser um simples ato de memorização e ensinar não significa repassar apenas os conteúdos prontos (Vieira, 2000). A prática da Pedagogia de Projetos visa a superação das habituais tendências em pedagogia, tendo como características, entre outras:

O aluno é sujeito da própria aprendizagem, não sendo um mero executor de atividades, mas muito mais co-participante;

A busca de informações pelos alunos é apenas orientada pelo professor, que não apresenta respostas prontas;

As práticas de sala de aula superam uma visão estática e descontextualizada, apoiando-se no real, na bagagem de conhecimentos que os alunos já trazem e no que, de fato, querem conhecer, não dependendo somente das escolhas dos adultos;

A elaboração e execução de projetos nas escolas não podem deixar de fora o conteúdo das disciplinas, mas pelo contrário, deve dinamizá-lo, enriquecê-lo, vinculando o processo de aprendizagem dos conteúdos a realidade atual (Oliveira, 1997). No trabalho com projetos os alunos não entram em contato com os conteúdos de maneira abstrata, ou de modo teórico, mas na busca das soluções de questões propostas no projeto, gera-se a necessidade da aprendizagem e, neste processo, os alunos se defrontam com os conteúdos das disciplinas, entendidos como instrumentos culturais valiosos para a compreensão da realidade.

O projeto na Pedagogia de Projetos é composto de quatro fases: Escolha do Tema Gerador; Coleta de Informações; Organização das Informações e Exposição das Informações.

Na primeira fase, o aluno irá juntamente com os colegas e professores, escolher o tema gerador do projeto. A sugestão do tema pode partir de um só aluno, do professor ou de um grupo de alunos. O importante é que esse problema envolva a todos e passe a ser de todos.

Um tema se chama gerador porque, qualquer que seja a natureza de sua compreensão, como a ação por ele provocada, contêm em si a possibilidade de 
desdobrar-se em outros tantos temas que, por sua vez, provocam novas tarefas que devem ser seguidas (Freire, 1987).

Após a escolha do tema, a continuidade ao trabalho será dada com os alunos coletando informações de diferentes tipos de fontes como conversas ou entrevistas com informantes diversos, passeios ou visitas, pesquisas bibliográficas, pesquisas na Internet, desenhos e outros.

A terceira fase do projeto, Organização das Informações, o aluno irá determinar o direcionamento final de seu projeto, que poderá ser um cartaz, jornal, história em quadrinhos, poesia, etc. e organizar o material que será apresentado. É importante que nesse momento utilizem-se diferentes fontes de modalidade para apresentar os diversos pontos de vista.

A última fase, Exposição das Informações Coletadas, o aluno irá expor o produto final na escola, para os colegas, professores e pais.

\subsection{Pedagogia de Projetos na Prática}

Com a intenção de verificar a validade e relevância de construção da ferramenta, foram realizadas visitas a duas escolas municipais que trabalham com a Pedagogia de Projetos atendendo crianças do Maternal I ao Ensino Fundamental. Estas auxiliaram também na definição de indicadores para a construção do KidWeb.

Uma das preocupações verificadas é a de trabalhar buscando estar atualizada nas propostas educacionais e oferecer as crianças as mais diferentes e diversas experiências. Para isso, baseia-se no Projeto Qualidade de Vida, o qual propõe a elaboração do currículo dividido em semanas nas quais são inseridos temas como "Semana do meio ambiente", "Semana das boas maneiras", "Semana das eleições", de acordo com datas comemorativas, eventos e interesse dos alunos. Os professores elaboram as atividades curriculares e interdisciplinares envolvendo-as ao tema proposto.

A grande maioria das atividades realizadas se encerram com a exposição das informações coletadas e organizadas pelos alunos. Normalmente são cartazes ou documentos feitos através do computador usando softwares como Word, Paint, kidpix e outros.

As escolas visitadas possuem laboratórios de informática onde são realizados projetos integrados aos conteúdos trabalhados em sala de aula, seguindo o contexto das semanas, utilizando o computador como mais uma ferramenta auxiliar ao desenvolvimento cognitivo das crianças.

As escolas expuseram a necessidade de software para suporte a essas atividades no Ensino Fundamental e pretendem integrar a Internet as disciplinas de sala de aula oferecendo ao aluno mais uma fonte de pesquisa e desenvolvimento de projetos.

Considerando estas questões, verificou-se que a construção do KidWeb poderia contribuir para a realização atividades relacionadas a Pedagogia de Projetos, uma vez que estas normalmente geram um produto final em forma de documento. A elaboração destes documentos utilizando um editor HTML, construído considerando as características da criança e da natureza das atividades, permite auxiliar no desenvolvimento das habilidades cognitivas, mudando a visão a respeito da Internet e possibilitando um acesso mais amplo aos trabalhos desenvolvidos em sala de aula. 


\section{Busca de Indicadores para a Interface}

A interface deve funcionar como ponte de acesso entre a criança e o sistema (Marucci, 1999). O primeiro passo no planejamento da interface é identificar a idade das crianças para as quais o projeto se destina, pois considerar o tipo de usuário e suas características é tarefa primordial para que os requisitos sejam atendidos. Definiu-se em conjunto com as especialistas das escolas visitadas que a faixa etária adequada para $o$ KidWeb compreende alunos $3^{\mathrm{a}}$ e $4^{\mathrm{a}}$ séries do Ensino Fundamental.

Com o objetivo de encontrar indicadores para o desenvolvimento das funcionalidades do software, analisou-se o Editor HTML Microsoft FrontPage Express. O software de autoria Fine Artist, foi analisado por ser uma ferramenta de autoria voltada para o público infantil e o editor HTML para crianças HotDog Junior por trabalhar com a mesma faixa etária do KidWeb.

\subsection{Análise do Software MS-FrontPage Express}

O FrontPage é um software disponível para plataforma Windows, possibilita criar e editar Websites em HTML. A tela principal, onde são confeccionadas as páginas contém barras de ferramentas para a formatação do documento, onde os botões presentes representam os comandos usados com maior frequiência.

Elaborar uma página HTML no Front Page é semelhante a elaborar um documento em um editor de textos. Com isso, não é necessário o conhecimento de HTML. A edição é visual, e o código correspondente é gerado automaticamente.

Os recursos mais comuns para composição de documentos eletrônicos encontramse presentes, como recortar, copiar, colar, voltar, formatar fonte, inserir imagens, formatar cor de fundo e assim por diante.

Para facilitar a organização dos textos e imagens de uma página da Web, o FrontPage permite o uso de tabelas as quais exibem de maneira semelhante a uma planilha, linhas e colunas nas quais poderão ser digitados os textos. Tanto as imagens como os textos poderão ser utilizados como hyperlinks, os quais apontam para outra página da Web, imagem ou tabela quando o visitante dá um clique sobre esta.

\subsection{Análise da Ferramenta Fine Artist}

A escolha desta ferramenta se deu pela mesma adequar-se ao público alvo do projeto proposto, possuir ícones identificados com a realidade das crianças e proporcionar à mesma um ambiente de autoria. A ferramenta Fine Artist permite à criança criar histórias em quadrinhos, figuras animadas, cartazes e adesivos.

O ambiente dispõe de ferramentas que buscam ensinar técnicas de artes, tal como noções de dimensão durante a elaboração de um desenho (Boff, 2000). Além disso, a capacidade imaginativa da criança pode ser demonstrada através da adição de sons e figuras animadas ao trabalho elaborado, bem como a utilização de figuras prontas. Possibilita a prática da escrita, a qual permite à criança a construção de palavras que podem ser associadas a sons e a efeitos visuais, como adição de cores.

O Fine Artist em primeiro momento pode confundir a criança, devido sua variedade de recursos, porém sua interface intuitiva e amigável facilita sua utilização. 
Salienta-se algumas características interessantes como:

1) Utilização de ícones com aparência adequada ao público infantil;

2) Adição de sons às palavras: os usuários podem utilizar os sons disponíveis no ambiente, bem como gravarem novos sons para serem adicionados às palavras (Boff, 2000);

3) Edição de figuras pertencentes ao acervo da ferramenta;

4) Cada aluno cria um diretório com seu nome, onde são gravados os trabalhos realizados no ambiente.

\subsection{Análise do HotDog Junior}

O HotDog Junior é um editor HTML para crianças cuja interface apresenta-se no idioma Inglês. O software possui um personagem próprio (cachorro) que apresenta as funções do editor.

O software é composto por um menu com botões relativamente grandes para escolher, construir, visualizar e salvar um documento HTML.

A criança pode criar uma página visualmente, selecionar a cor de fundo e adicionar itens como imagens, textos, links etc.

Os textos são digitados em uma caixa de texto própria, e para formatar o texto abre-se uma caixa de diálogo com uma série de opções onde a criança escolhe o estilo da letra, cor e alinhamento do texto.

Para adicionar figuras, abre-se uma caixa de diálogo onde a criança pode escolher aquela que desejar. Os itens escolhidos são distribuídos na página conforme a ordem que a criança os insere. A criança pode ainda visualizar a página e salvá-la. 


\section{Descrição do KidWeb}

Para o desenvolvimento de um projeto de software educacional é necessário abordar os aspectos técnicos e pedagógicos. A escolha da taxonomia é importante para determinar as características predominantes no software e orientar o processo de modelagem e implementação. O KidWeb enquadra-se na modalidade de ferramenta de autoria, pois o mesmo possibilita ao aluno explorar um conjunto amplo de habilidades cognitivas exercendo sua criatividade.

Decidiu-se pela disponibilização de quatro modelos de páginas pré-elaboradas com locais definidos para a inserção de título, textos, imagem e links. Considera-se que assim a criança terá maior facilidade para elaborar a página, característica importante de softwares desenvolvidos para este público. A Fig. 1 ilustra a tela de escolha de um modelo.

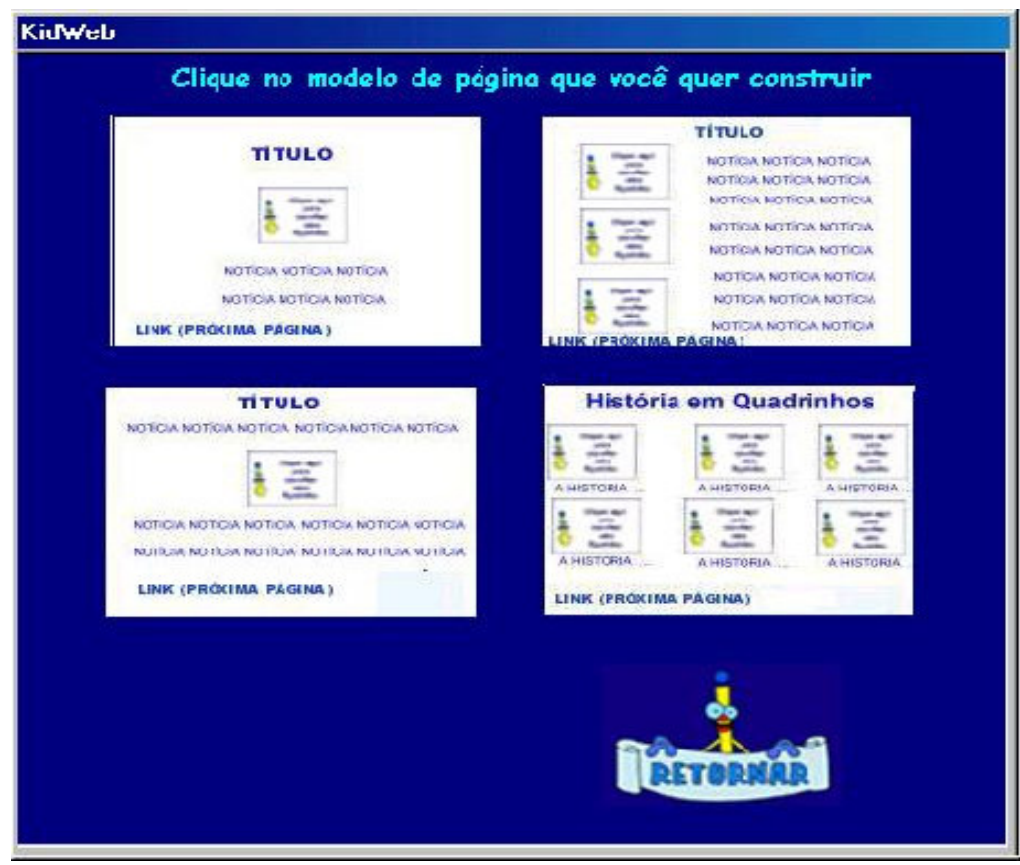

Fig 1. Tela de seleção de um modelo

As funcionalidades definidas para o editor foram baseadas no FrontPage, são elas: "Inserir Marcadores", "Formatar Parágrafo", "Recortar", "Copiar", "Colar", "Inserir Cor de Fundo", "Salvar", "Imprimir" "Visualizar Página" e "Ajuda". Estas foram selecionadas por serem as tarefas mais básicas que possibilitam a elaboração de websites.

Através da análise do HotDog Junior, constatou-se a importância do software possuir um personagem próprio para que a criança possa criar uma identificação com este. Com isso, criou-se o personagem Izinho (I de Internet), que tem o amarelo como padrão de cor e tamanho relativamente grande para facilitar a identificação e o clique do mouse. A figura foi elaborada considerando a linguagem e representação das crianças da faixa-etária a que o software se destina. $\mathrm{O}$ personagem pode ser visualizado em detalhe na Fig. 2. 


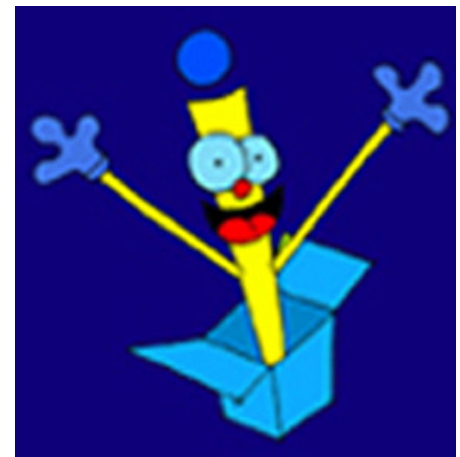

Fig. 2. Personagem Izinho do KidWeb

A tela principal onde é confeccionada a página é composta pela área de edição no centro e os ícones a sua volta. Isto permite ao aluno ter uma visibilidade maior dos ícones e passa a idéia de um ambiente descontraído e agradável.

O software desempenha funções básicas como: criar um novo documento HTML baseado no modelo escolhido, salvar este documento, inserir figuras, texto, hiperlinks, formatação e outros. A Fig. 3 ilustra a interface do KidWeb com um modelo para elaboração de história em quadrinhos.

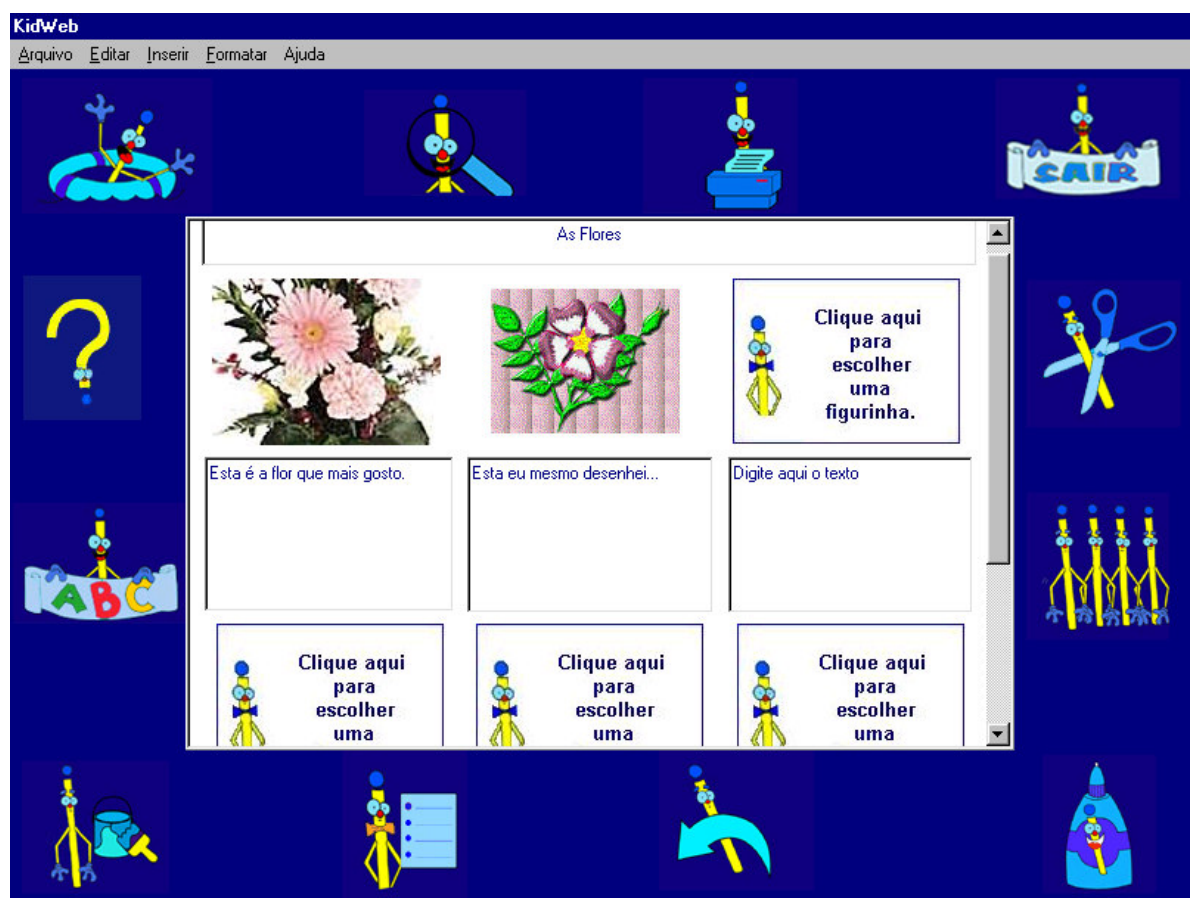

Fig. 3. Interface do KidWeb

A criança desenvolve a página da maneira que desejar, pois a formatação das letras, cores de fundo e imagem são inseridos de acordo com a sua imaginação. A visualização da página poderá ser feita utilizando-se o visualizador do KidWeb. A Fig. 4 demonstra uma página elaborada no KidWeb. 


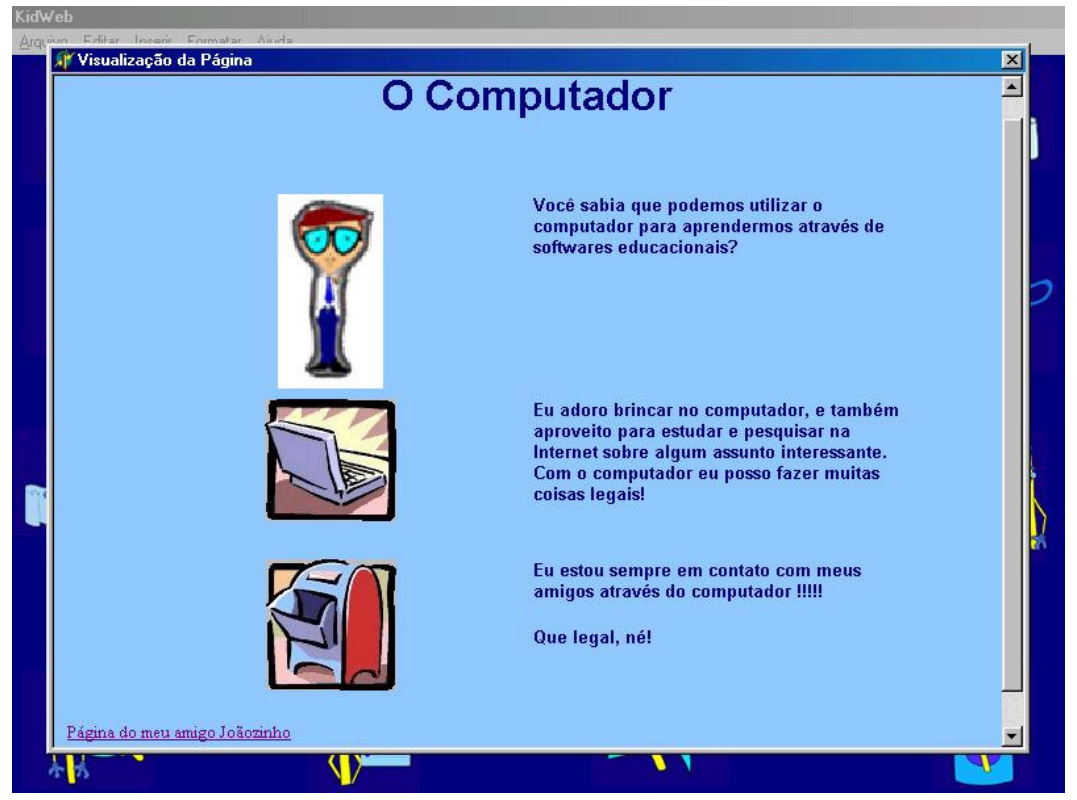

Fig. 4. Página elaborada no KidWeb

A criança não necessita ter conhecimento de HTML para desenvolver suas atividades no KidWeb, pois o mesmo é um software visual, ou seja, a medida em que a página vai sendo construída, o código HTML é gerado automaticamente.

O KidWeb possibilita ao professor selecionar a pasta padrão a qual o software buscará pelos arquivos de imagem. Desta forma podem-se construir um acervo de imagens relacionadas ao Tema Gerador selecionado. A pasta onde os documentos HTML ficam gravados também pode ser selecionada, e caso de ser uma pasta pública comum a rede local da escola, facilita a tarefa de reunir os trabalhos realizados pelas crianças em um dossiê digital que poderá ser exposto através da Internet para outras crianças, pais, coordenadores, etc. 


\section{KidWeb e a Pedagogia de Projetos}

A relação entre o KidWeb e a pedagogia de projetos fica mais clara ao se analisar as etapas isoladamente. Na fase de Coleta de Informações, a criança e o professor podem coletar ou construir (através de softwares como o Paint) um acervo de imagens e dispô-las para os colegas elaborarem seus websites. Para isso, o KidWeb fornece a escolha de uma pasta padrão de onde são buscadas as imagens. Esta pasta pode ser compartilhada entre os vários usuários, e pode variar conforme o desejo do professor, ou conforme o tema gerador.

Na etapa de Organização das Informações, a criança poderá utilizar-se do KidWeb para organizar o projeto em forma de website usando um dos modelos disponíveis. Poderá ser um texto individual, poesia, história em quadrinhos, jornalzinho, relato de uma entrevista, etc.

$\mathrm{Na}$ última fase, Exposição das Informações Coletadas, é importante que a criança possa divulgar o que está fazendo e tenha a oportunidade de comunicá-lo. Os dossiês são uma estratégia importante para a organização final dos projetos. Dentro deste contexto, o KidWeb servirá como uma porta de acesso para a divulgação dos projetos na Internet e uma nova possibilidade na utilização de uma ferramenta para a construção de páginas totalmente voltada à criança.

Assim, o uso da informática nas instituições educacionais, que inicialmente era vista apenas como uma disciplina complementar na carga curricular dos alunos, passa a ser vista como uma ferramenta de auxílio ao aprendizado. 


\section{Considerações Finais}

A Pedagogia de Projetos surgiu como um motivador para a realização deste trabalho, uma vez que as características das tarefas realizadas e o suporte fornecido pelas ferramentas de software indicavam a possibilidade de utilização de uma ferramenta de autoria voltada para Internet, um editor de páginas HTML.

Sabe-se, porém que a ferramenta não limita-se as atividades de Pedagogia de Projetos, uma vez que esta pode ser utilizada através de outras abordagens ou simplesmente usada sem uma contextualização.

O envolvimento dos especialistas em Educação das escolas visitadas permitiu elucidar o potencial intrínseco da ferramenta. O domínio da técnica de construção de websites pelas crianças pode trazer como consequiência positiva uma visão crítica frente à informação disponível na rede, deixando de ser apenas consumidora e passando também a ser produtora de informações.

Outros fatores positivos estão relacionados a facilidade de acesso aos trabalhos produzidos por alunos nas escolas, permitindo a visitação de pais, colegas de outras escolas, ou mesmo de comunidades infantis como o Kidlink (Lucena, 1998).

Além disso, a Internet permite a criança um contato mais direto com o mundo, o que atende a mais uma necessidade atual: a da experiência direta como modalidade de aprendizagem mais propícia ao desenvolvimento da capacidade de resolução criativa de problemas (Sobral, 1999).

Acredita-se que o KidWeb pode se tornar uma ferramenta de grande valia para as crianças, atuando como uma ferramenta incentivadora no processo de ensino/aprendizagem das escolas. No presente momento, estão sendo programados experimentos para avaliação do KidWeb em atividades de aprendizagem nas escolas. Os resultados desta avaliação deverão ser explorados em trabalhos futuros.

\section{Agradecimentos}

Os autores gostariam de agradecer ao Colégio Aplicação UNIVALI e aos Professores Sonia Cabral, Yára Cesário e Dorinel Fortunatto. 


\section{Referências Bibliográficas}

Boff, Elisa. Giraffa, Lúcia M.M. Criação de Histórias em Quadrinhos de forma cooperativa na Web. Simpósio Catarinense de Computação, anais p. 639-649, Itajaí 2000.

Freire, Paulo. Pedagogia do Oprimido. Editora Paz e Terra, Rio de Janeiro, 1987.

Lucena, Marisa. Comunidades Dinâmicas para Aprendizado na Internet. Revista Brasileira de Informática na Educação N² 2. Abril, 1998.

Marucci, R. A. Projeto de Interface e Multimídia para Crianças. Workshop de Informática na Escola, Congresso Nacional da Sociedade Brasileira de Computação, anais p. 759-770, Rio de Janeiro, 1999.

Oliveira, R. Informática Educativa: Dos Planos e Discursos à Sala de Aula. Campinas: SP, Papirus, 1997.

Sobral, Adail. Internet na escola - O que é, como se faz. São Paulo: Edições Loyola, 1999.

Vieira, Fábia Magali Santos. Pedagogia de Projetos. Disponível em: <http://www.connect.com.br/ntemg/pedagp.htm> Acesso em 23 jun. 2000. 